\title{
ROTARY FRICTION WELDING OF WEIGHT HEAVY ALLOY WITH WROUGHT AIMg3 ALLOY FOR SUBCALIBER AMMUNITION
}

\author{
Olgierd Goroch ${ }^{1}$, Zbigniew Gulbinowicz' \\ 1 Institute of Mechanics and Printing, Faculty of Production Engineering, Warsaw University of Technology, \\ ul. Narbutta 85, 02-524 Warszawa, Poland, e-mail: o.goroch@wip.pw.edu.pl, zgulbinowicz@interia.pl
}

Received: 2017.08.23

Accepted: 2017.11.01

Published: 2017.12.05

\begin{abstract}
The results of studies concerning friction welding of Weight Heavy Alloy (WHA) with AlMg3 alloy are presented. The friction welding of density $17.5 \mathrm{Mg} / \mathrm{m}^{3}$ with aluminum alloy showed that it is possible to reach the joints with the strength exceeding the yield strength of wrought AlMg3 alloy. This strength looks to be promising from point of view of condition which have to be fulfilled in case of armor subcaliber ammunition, where WHA rods play the role Kinetic Energy Penetrators and aluminum is used for projectile ballistic cup.
\end{abstract}

Key words: friction welding, weight heavy alloys, subcaliber ammunition

\section{INTRODUCTION}

Heavy alloys, apart from many other applications, are used among other to the cores for sub-calibre ammunition (Kaczorowski, et al., 2006). To avoid the ricochet, sub-calibre ammunition cores are supplied in bonnets ballistic (Fig. 1) made of $\mathrm{Al}$ alloy. So far, a combination of the WHA - aluminum alloy is a combination of a screw which significantly increases not only the manufacturing process but also makes it more expensive due to the necessity of machining extremely inconvenient tungsten alloy.

One might expect that the problem of combining doesn 't exist and indeed it is so in the case of conventional materials, especially when it comes to combining similar materials. Very high melting point of tungsten, reaching up to $3420^{\circ} \mathrm{C}$ causes the tungsten heavy alloys are generally prepared by sintering with liquid phase - LPS. This results in a specific microstructure of these alloys, which are is often referred as tungsten composites. Quite different with the issue of joining is the WHA alloy aluminum. They vary in mechanical properties, melting point, the coefficients of linear thermal expansion, etc., which negatively affects the combination of these materials (Ambroziak, et al., 2007) (Ambroziak, 2011) (Ambroziak, 1998) (Kaczorowski, 2002). However, preliminary attempts to combine WHA - AlMg3 alloy friction welding method has shown that it is prospective, it allows to make connections with tensile strength at close-strength aluminum alloy (Kaczorowski, et al., 2008).

\section{MATERIAL FOR TESTING AND METHODS}

To complete the connectors used: tungsten heavy alloy is obtained in the laboratory of heavy alloys Warsaw University of Technology of powder metallurgy with a density of $17.5 \mathrm{Mg} / \mathrm{m}^{3}$ and AlMg3 (BS EN 573-3:2009) in the form of a rod. Details of the manufacturing process of tungsten alloy are specified in (Kaczorowski, et al., 2008). Welding was performed with different setting values using the clamping force of friction and the friction time, maintaining a constant value of the upset force and the time of upsetting of respectively: $\mathrm{F}_{\mathrm{S}}=50 \mathrm{kN}$ and $\mathrm{t}_{\mathrm{S}}=5 \mathrm{~s}$ (Table 1).

Samples AlMg3 were prepared for welding in the form of rods having a diameter of 


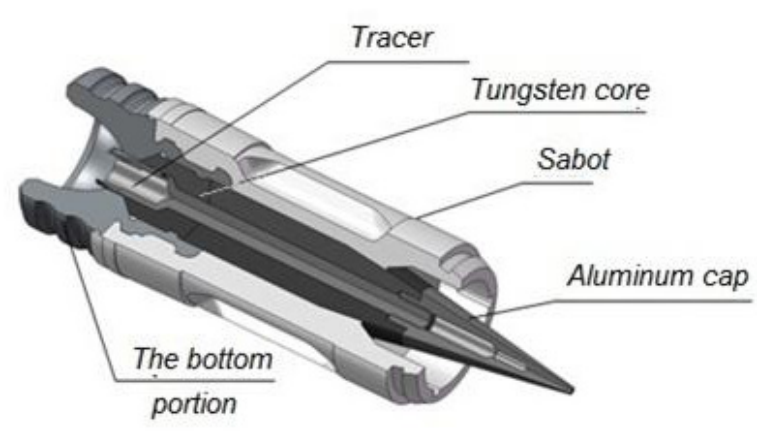

Fig. 1. Schematic diagram of APDS projectile

Table 1. The parameters of friction welding process

\begin{tabular}{|c|c|c|}
\hline \multirow{2}{*}{ Sample number } & Friction time & $\begin{array}{l}\text { Strength in the } \\
\text { period friction }\end{array}$ \\
\hline & $t_{t}[s]$ & $\mathrm{F}_{\mathrm{t}}[\mathrm{kN}]$ \\
\hline 1 & 7 & 10.0 \\
\hline 2 & 10 & 20.0 \\
\hline 3 & 7 & 20.0 \\
\hline 4 & 10 & 10.0 \\
\hline 5 & 3.5 & 20.0 \\
\hline 6 & 6.5 & 30.0 \\
\hline 7 & 3.5 & 30.0 \\
\hline 8 & 6.5 & 20.0 \\
\hline 9 & 6.5 & 12.5 \\
\hline 10 & 9.5 & 22.5 \\
\hline 11 & 6.5 & 22.5 \\
\hline 12 & 9.5 & 12.5 \\
\hline 13 & 4.5 & 12.5 \\
\hline 14 & 7.5 & 22.5 \\
\hline 15 & 4.5 & 22.5 \\
\hline 16 & 7.5 & 12.5 \\
\hline 17 & 4.5 & 12.5 \\
\hline 18 & 7.5 & 22.5 \\
\hline 19 & 4.5 & 22.5 \\
\hline 20 & 7.5 & 12.5 \\
\hline 21 & 4.5 & 12.5 \\
\hline 22 & 7.5 & 22.5 \\
\hline 23 & 4.5 & 22.5 \\
\hline 24 & 7.5 & 12.5 \\
\hline 25 & 4.5 & 15.0 \\
\hline 26 & 7.5 & 25.0 \\
\hline 27 & 4.5 & 25.0 \\
\hline 28 & 7.5 & 15.0 \\
\hline 29 & 0.5 & 12.5 \\
\hline 30 & 3.5 & 22.5 \\
\hline 31 & 0.5 & 22.5 \\
\hline 32 & 3.5 & 12.5 \\
\hline
\end{tabular}

$20 \mathrm{~mm}$ and a length $100 \mathrm{~mm}$. A total of 32 pairs of connectors made WHA-AlMg3 welding parameters for variables according to the plan two-level theory of experiment planning. After welding process, samples cooled in air. Collected connectors (Alves, et al., 2010) (Gregson \& Harris, 2002) were tested in order to designate tear strength, and microscopic observations were performed of the WHA and AlMg3. Tests were performed on a testing machine on mini-samples of two kinds. The mini-samples were brought from the fragments obtained after cutting the rods welded along their axes into four quadrants, and the second full-sized samples, which had a diameter of the gripping portion about $20 \mathrm{~mm}$, and accordingly the lower part of the connector. In addition, tests were performed in the hardness distribution function of distance from the plane of the connector.

\section{TEST RESULTS}

Figure 2 shows examples of connections samples WHA - AlMg3 for friction welding, using the variables of the process. The flash connectors are characterized by a cone-shaped or cup-size-dependent friction welding parameters. The shape of the bead also due to non-similarities joined materials. Burrs were removed on the lathe before tearing strength tests.

\section{The results of mechanical properties}

\section{The results of tensile strength}

The results of tensile strength tests are given in the table 2. Table 2 shows that in the case of the three calls were obtained stress values burst above $200 \mathrm{MPa}$, which is similar as the yield strength of the alloy AlMg3. It is also worth noting that the scatter of tensile strength test results, in most cases, is not large.

\section{The results of hardness measurements}

Vickers hardness tests performed using a load $\mathrm{F}=1 \mathrm{~N}$. Figure 3 is an exemplary plot that illustrates the change of hardness as a function of distance from the plane of the welding part made the WHA and aluminum alloy.

Figure 3 shows that friction welding does not affect the course of changes in the hardness 
a)

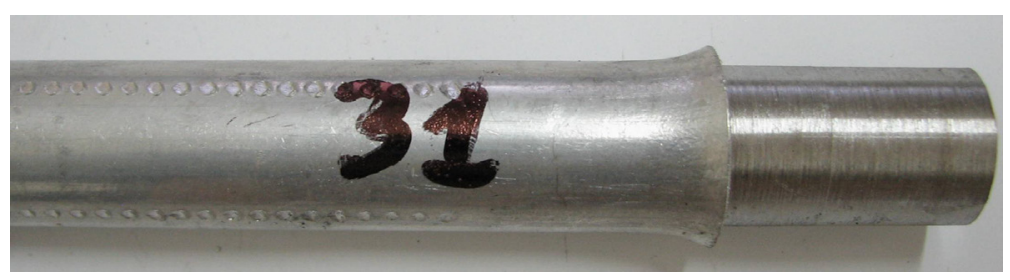

b)

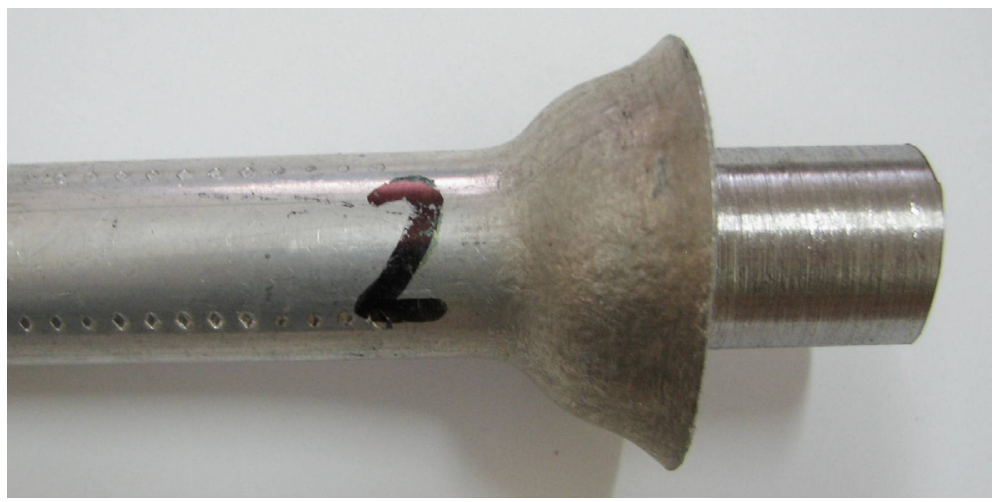

Fig. 2. The examples of friction welded WHA-AlMg3 joints obtained for: $\mathrm{a}-\mathrm{FS}=22.5 \mathrm{kN}$ and $\mathrm{tS}=0.5 \mathrm{~s}, \mathrm{~b}-\mathrm{FS}=20 \mathrm{kN}$ ant $\mathrm{tS}=10 \mathrm{~s}$

Table 2. The results of tensile strength experiment on selected of mini samples

\begin{tabular}{|c|c|c|c|c|c|}
\hline \multirow{2}{*}{$\begin{array}{l}\text { Sample } \\
\text { number }\end{array}$} & \multicolumn{2}{|c|}{ Welding parameters } & \multirow{2}{*}{$\begin{array}{c}\text { Tensile strength } \\
\mathrm{F}_{\max } \cdot[\mathrm{kN}] \\
\end{array}$} & \multirow{2}{*}{$\begin{array}{c}\text { Stress bursting } \\
\sigma_{r}[\mathrm{MPa}]\end{array}$} & \multirow{2}{*}{$\begin{array}{l}\text { The average value of the stress burst } \\
\qquad \sigma^{\mathrm{sr}}{ }_{\mathrm{r}}[\mathrm{MPa}]\end{array}$} \\
\hline & $\mathrm{t}_{\mathrm{T}}[\mathrm{s}]$ & $\mathrm{F}_{\mathrm{T}}[\mathrm{kN}]$ & & & \\
\hline $1 \mathrm{a}$ & \multirow{2}{*}{7.0} & \multirow{2}{*}{10} & 4.49 & 144.04 & \multirow{2}{*}{146.6} \\
\hline $1 \mathrm{~b}$ & & & 4.68 & 149.18 & \\
\hline $3 a$ & \multirow[b]{2}{*}{7.0} & \multirow[b]{2}{*}{20} & 5.03 & 177.01 & \multirow{2}{*}{163.6} \\
\hline $3 b$ & & & 4.78 & 150.22 & \\
\hline $4 a$ & \multirow{2}{*}{10.00} & \multirow{2}{*}{1.00} & 5.18 & 195.38 & \multirow{2}{*}{202.6} \\
\hline $4 b$ & & & 6.00 & 209.75 & \\
\hline $5 a$ & \multirow{2}{*}{3.50} & \multirow{2}{*}{20.0} & 5.44 & 190.49 & \multirow{2}{*}{192.4} \\
\hline $5 b$ & & & 5.27 & 194.40 & \\
\hline $6 a$ & \multirow{2}{*}{6.50} & \multirow{2}{*}{30.0} & 4.20 & 158.15 & \multirow{2}{*}{141.0} \\
\hline $6 b$ & & & 2.00 & 123.82 & \\
\hline $7 a$ & \multirow{2}{*}{3.50} & \multirow{2}{*}{30.0} & 4.15 & 162.92 & \multirow{2}{*}{166.6} \\
\hline $7 \mathrm{~b}$ & & & 4.27 & 170.31 & \\
\hline $8 a$ & \multirow{2}{*}{6.50} & \multirow{2}{*}{20.0} & 4.13 & 192.61 & \multirow{2}{*}{175.6} \\
\hline $8 b$ & & & 4.35 & 158.57 & \\
\hline $10 a$ & \multirow[b]{2}{*}{9.50} & & 4.24 & 140.21 & \\
\hline $10 \mathrm{~b}$ & & 22.5 & 3.76 & 136.83 & 138.5 \\
\hline $11 a$ & & & 3.78 & 137.10 & \\
\hline $11 \mathrm{~b}$ & 6.50 & 22.5 & 3.60 & 132.80 & 135.0 \\
\hline $12 a$ & & & 6.71 & 228.48 & \\
\hline $12 \mathrm{~b}$ & 9.50 & 12.5 & 7.15 & 234.55 & 231.5 \\
\hline $14 a$ & & & 3.63 & 138.34 & \\
\hline $14 b$ & 7.50 & 22.5 & 3.64 & 124.76 & 131.5 \\
\hline $15 a$ & 450 & & 3.35 & 147.09 & \\
\hline $15 b$ & 4.50 & 22.5 & 4.33 & 144.59 & 145.8 \\
\hline $20 a$ & & & 4.53 & 175.06 & \\
\hline $20 \mathrm{~b}$ & 7.50 & 12.5 & 4.52 & 174.98 & $1 / 5.0$ \\
\hline $25 a$ & & & 4.34 & 156.88 & \\
\hline $25 b$ & 4.50 & 15.0 & 4.55 & 153.17 & 155.0 \\
\hline $26 a$ & & & 3.42 & 131.25 & \\
\hline $26 \mathrm{~b}$ & 7.50 & 25.0 & 3.95 & 136.95 & 134.1 \\
\hline $29 a$ & & & 2.87 & 98.53 & \\
\hline $29 \mathrm{~b}$ & 0.50 & 12.5 & 2.81 & 95.52 & 97.0 \\
\hline $30 a$ & & & 4.59 & 171.65 & \\
\hline $30 \mathrm{~b}$ & 3.50 & 22.5 & 4.17 & 173.30 & 172.5 \\
\hline $32 a$ & & & 6.52 & 230.98 & 2343 \\
\hline $32 \mathrm{~b}$ & 3.50 & 12.5 & 6.81 & 237.67 & 234.3 \\
\hline
\end{tabular}


a)

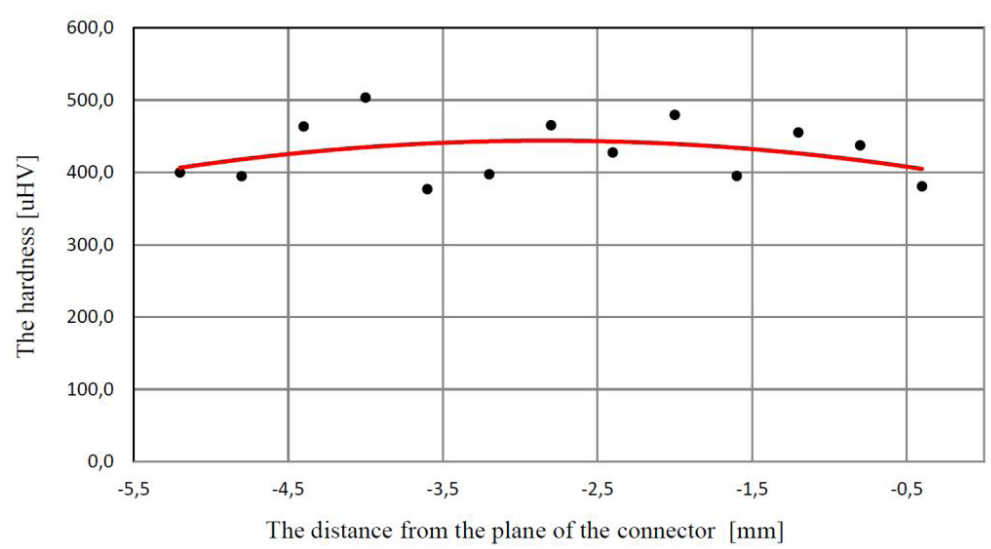

b)

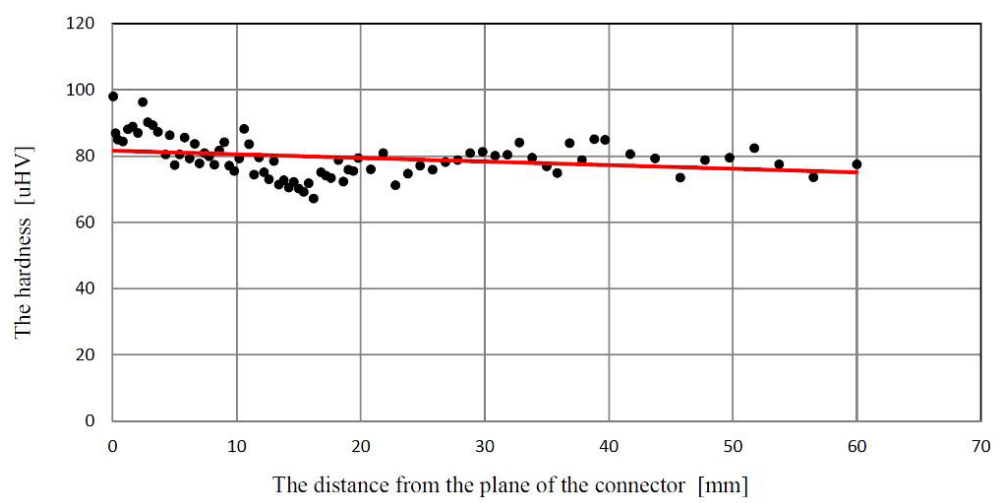

Fig. 3. The example of microhardness variation in friction welded WHA-AlMg3 specimen as a function of distance from joint plane: $\mathrm{a}$ - in WHA and $\mathrm{b}$ - in AlMg3 alloy

of the alloy WHA, and observed fluctuations are an intrinsic characteristic of microhardness tests. In contrast to the chart for the WHA, the course changes the hardness of the alloy AlMg3 (Fig. $3 b)$ shows a clear influence of the welding process on the distribution of hardness as a function of distance from the plane of the connector. The strengthening layer can be seen near the joints, for which, in the range of $10-20 \mathrm{~mm}$.

The next diagrams show the distribution of the hardness of the alloy as a function of distance from the axis of pooled samples of measured parallel to the plane of the connector at a distance from the $\mathrm{x}=1,2,4$ and $6 \mathrm{~mm}$. Their goal was to determine how it affects all the time to change the hardness of the friction in the joints, which is a reflection of changes in structure (in the work presented only the results of which reached the highest tensile strength). Friction welding process causes the heating of the materials to be joined, the amount of heat generated depends on the welding parameters, so the clamping force $\mathrm{F}_{t}$ and the time $t_{t}$ friction. Due to the fact that the peripheral speed is connected on the periphery of the largest samples, therefore heat is primarily gen- erated in these areas and then forwarded in the direction of their axis.

\section{ANALYSIS OF RESULTS}

Obtained by using various experimental techniques are valuable burrs visual observation geometry, and the measurement of changes in the dimensions for the various parameters bead friction welding process. The first is they will be discussed, because the size of burrs is a reflection of the volume of material deformed under the influence of the work done during the welding process. Figure 5 lists the shape of the connections function of time in frictional clamping force $\mathrm{F}_{\mathrm{t}}=12.5$ $\mathrm{kN}$ and $22.5 \mathrm{kN}$. Although it would seem logical that the $\mathrm{F}_{\mathrm{t}}=$ constant, the volume of material deformed (bead diameter) should increase steadily with increasing friction time Fig. 5 does not confirm this (e.g., sample No. 13 and 12). There is mistake in reasoning, and only shows the influence of disturbances, which can not be avoided during the welding process and the reasons did not manage to identify. In the fact that they were 
a)

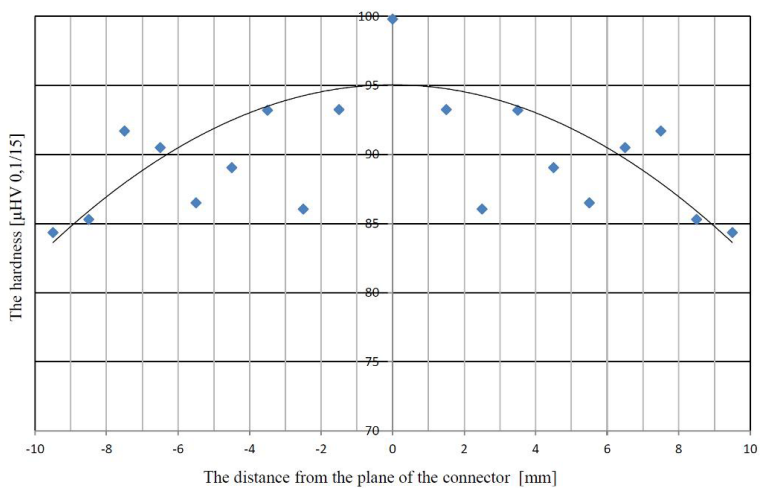

c)

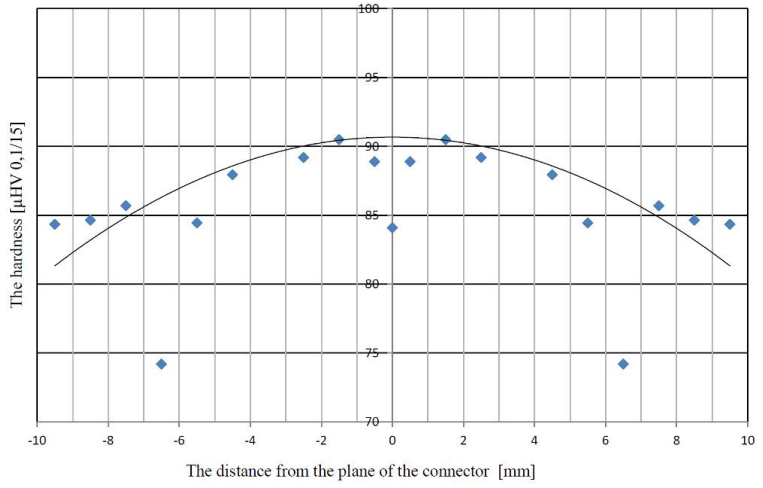

b)

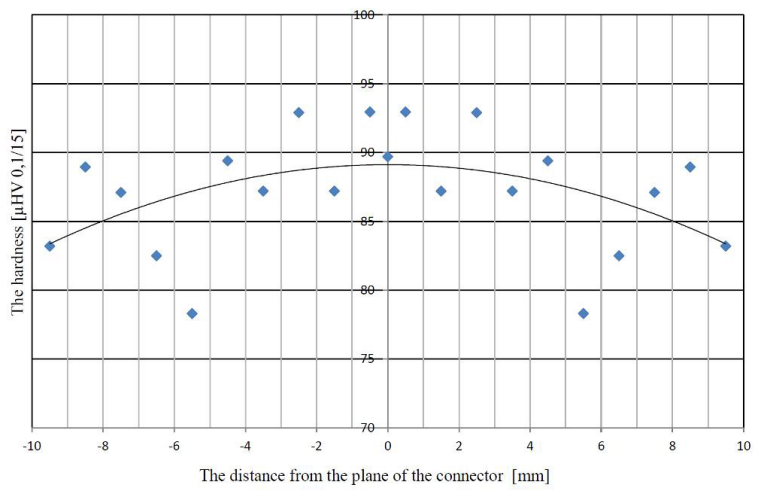

d)

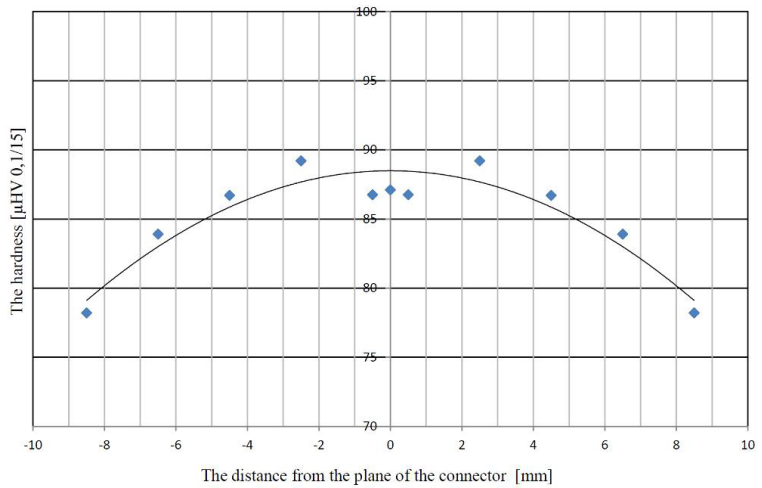

Fig. 4. HV0 hardness distribution, $1 / 15$ frictionally welded PA2 melt at $\mathrm{Ft}=12.5 \mathrm{kN}$ and $\mathrm{tt}=9.5 \mathrm{~s}$ as a function of distance from the axis of the sample measured in the plane of the remote from the plane of the connector: $a-x=1 \mathrm{~mm}, \mathrm{~b}-\mathrm{x}=2 \mathrm{~mm}, \mathrm{c}-\mathrm{x} 4 \mathrm{~mm}$ and $\mathrm{d}-\mathrm{x}=6 \mathrm{~mm}$

not the result of contamination of the samples, since before the beginning of the process of combining welded surfaces were thoroughly cleaned and degreased with alcohol.

In Figure 6 a chart illustrating the variation of the average cumulative volume of the bead as a function of the product of the clamping force during the friction and friction time $-\mathrm{F}_{\mathrm{t}} \times \mathrm{t}_{\mathrm{t}}$. However, the measurement points are characterized by a considerable scatter, resulting from the disruption of the process, as mentioned earlier (Fig. 5), however, the graph shows a systematic increase in the volume of the bead with the increase of product $\mathrm{F}_{\mathrm{t}} \times \mathrm{t}_{\mathrm{t}}$.

A product may be regarded as a reflection of the amount of heat produced during friction, which causes heating of the volume the greater the greater the friction work was done. Gradual reduction of the diameter of the bead increase with an increase in the product of $F_{t} \times t_{t}$ due to the fact change the geometry of the bead as you can see on Figure 7. As shown in Figure 7 at the beginning of the flash is the nature of the cone, which cross section can be approximated by a triangle. With the increase of friction work very clearly the cone changes shape in the direction of the cup, followed by the eversion occurs. If one considers that, in all welding trials upsetting force $\mathrm{F}_{\mathrm{s}}=50 \mathrm{kN}$ and upsetting time $\mathrm{t}_{\mathrm{s}}=5 \mathrm{~s}$ were always the same, therefore, discloses a deformed volume the volume of material that has reached a high enough temperature to under the force of the plastic deformation was $\mathrm{F}_{\mathrm{s}}$ "softened" material. It is obvious that the larger the volume the greater the shortening of the bead sample, which is undesirable.

Another point of discussion is an attempt to find a relationship between the strength of joints WSC- AlMg3 tear and friction work represented by the product of $F_{t} \times t_{t}$. Suitable tensile strength graph $R_{r}=f\left(F_{t} \times t_{t}\right)$ is shown in figure 8 .

In Figure 8 shows that the strength of the connections WHA - AlMg3 tear depends the product of melting and $F_{t}$ has a maximum in the region between 60 and $140 \mathrm{kN} \cdot \mathrm{s}$. From the graph you can see that, for several combinations of parameters of friction welding, resistance to tearing connector exceeds the yield strength of the alloy 

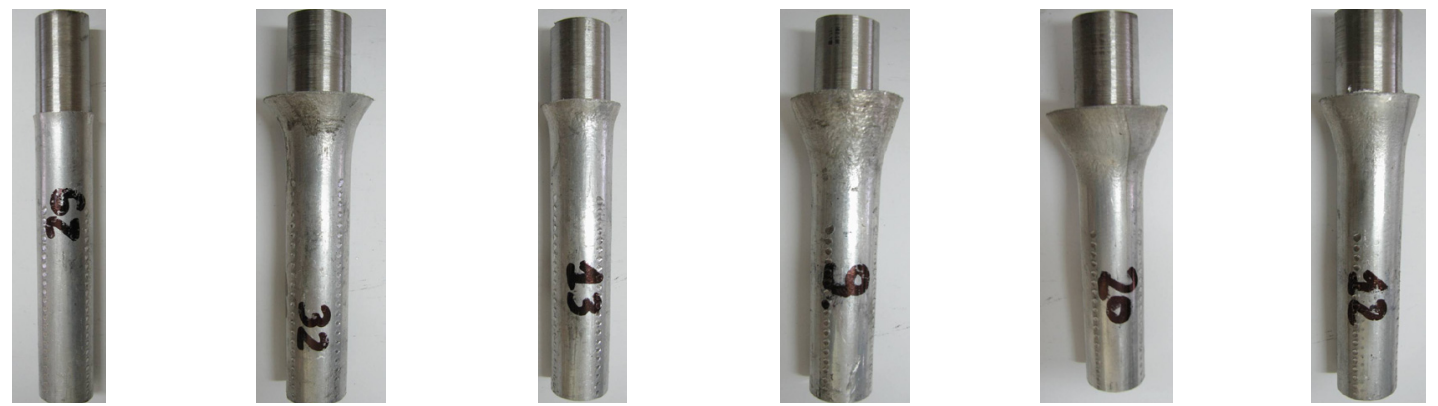

Pressing force $\mathrm{Ft}=12.5 \mathrm{kN}$

$\mathrm{tt}=0.5 \mathrm{~s}$

$\mathrm{tt}=3.5 \mathrm{~s}$

$\mathrm{tt}=4.5 \mathrm{~s}$

$\mathrm{tt}=6.5 \mathrm{~s}$

$\mathrm{tt}=7.5 \mathrm{~s}$

$\mathrm{tt}=9.5 \mathrm{~s}$

Time pressure $[\mathrm{s}]$
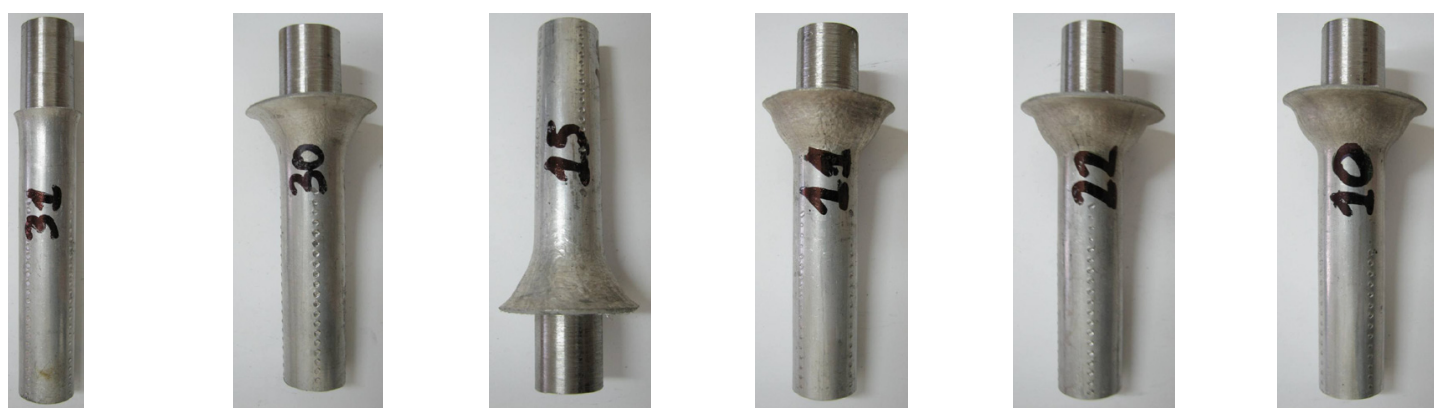

Pressing force $\mathrm{Ft}=22.5 \mathrm{kN}$

$\mathrm{tt}=0.5 \mathrm{~s} \quad \mathrm{tt}=3.5 \mathrm{~s}$

$\mathrm{tt}=4.5 \mathrm{~s}$

$\mathrm{tt}=6.5 \mathrm{~s}$

$\mathrm{tt}=7.5 \mathrm{~s}$

$\mathrm{tt}=9.5 \mathrm{~s}$

Time pressure $[\mathrm{s}]$

Fig. 5. Summary geometry burrs for a fixed clamping force $F_{t}=12.5 \mathrm{kN}$ and $\mathrm{F}_{\mathrm{t}}=22.5 \mathrm{kN}$ for variable time pressure

AlMg3, which was about $200 \mathrm{MPa}$. In such cases, the side surface of the aluminum alloy specimens connector forming the WHA - AlMg3 tensile characteristic was observed puckering caused by rotation of the surface of the grains (Fig. 9), and sometimes also parallel strands, which may be interpreted as steps of departure formed by the free surface of the sample to a series of moving dislocation slip systems (Fig.9b).

The constriction can be seen Fig. 9c undercut area AlMg3 of the sample alloy, while on the surface of larger diameter is shown "wrinkling". Fig. $9 \mathrm{~d}$ shows an example of the neck formed at a considerable distance from the plane of the connector in the samples without undercut, used during the first stage of research WHA friction welding alloy AlMg3. The latter image shows that the tensile connectors WHA - AlMg3, after exceeding the yield strength, the aluminum alloy is strengthened by deformation to the stress level, which turns out to be greater than the tear strength of the joint. It should be recognized that there is a connector in the plane of a complex state of stress, because, in addition to axial tensile stresses, shear stresses acting there over five times due to the linear expansion coefficient difference. During the cooling portion of the stress is relaxed by the plastic deformation of the alloy $\mathrm{AlMg} 3$ at a time when the temperature is high enough to allow plastic flow under low load (creep), it is part of them remain in the material to give a contribution to the prevailing state of stress in the joint. They argue that attempts to WHA with steel welding, during which there have to "self-destruct" call WHA - steel during relatively free samples free cooling after welding [10].

Another issue to be discussed are a little closer to the hardness as a function of the welding process parameters. Comparing the graphs HV as a function of distance from the plane to the terminal clamping force of friction $\mathrm{F}_{\mathrm{t}}=22.5 \mathrm{kN}$ and $F_{t}=12.5 \mathrm{kN}$ you will see that although they are similar, but the maximum hardness at the interface just after the time of friction $t_{t} \geq 3.5 \mathrm{~s}$ is clearly higher (Fig. 3). It is noteworthy that the hardness as a function of the distance from the connector for $\mathrm{F}_{\mathrm{t}}=22.5 \mathrm{kN}$ is most pronounced for the time of friction of 3.5 and $4.5 \mathrm{~s}$, and further 


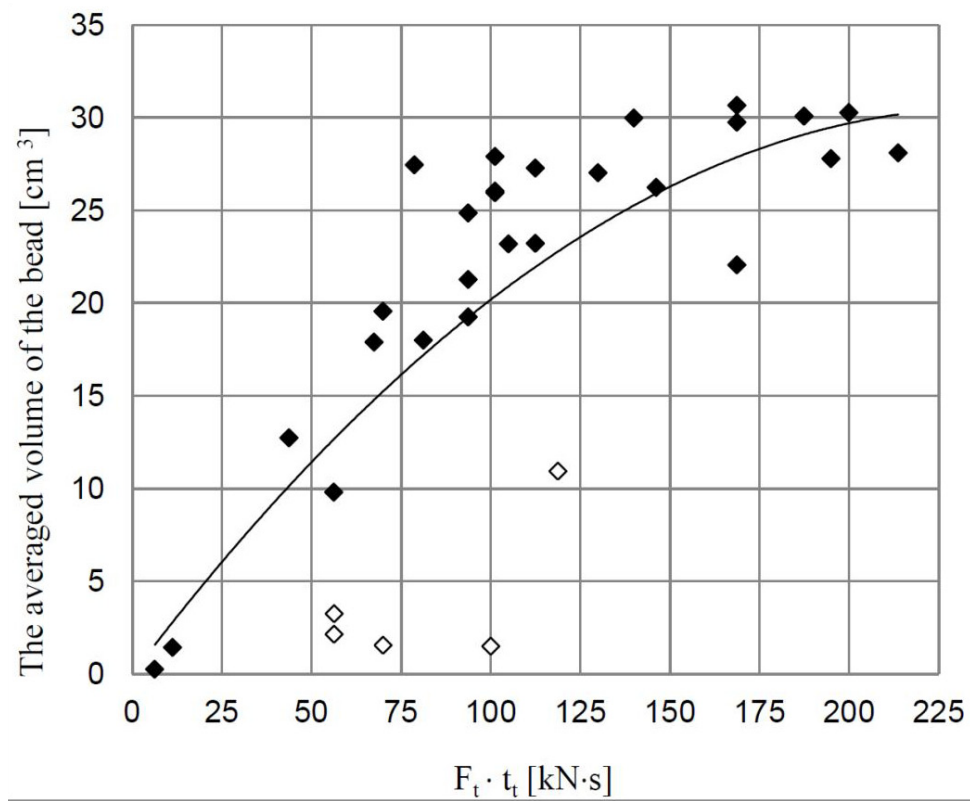

Fig. 6. Chart bead volume as a function of the product of the pressure force Ft and the friction time tt (bright dots indicate measurement values clearly deviate from the trend line)

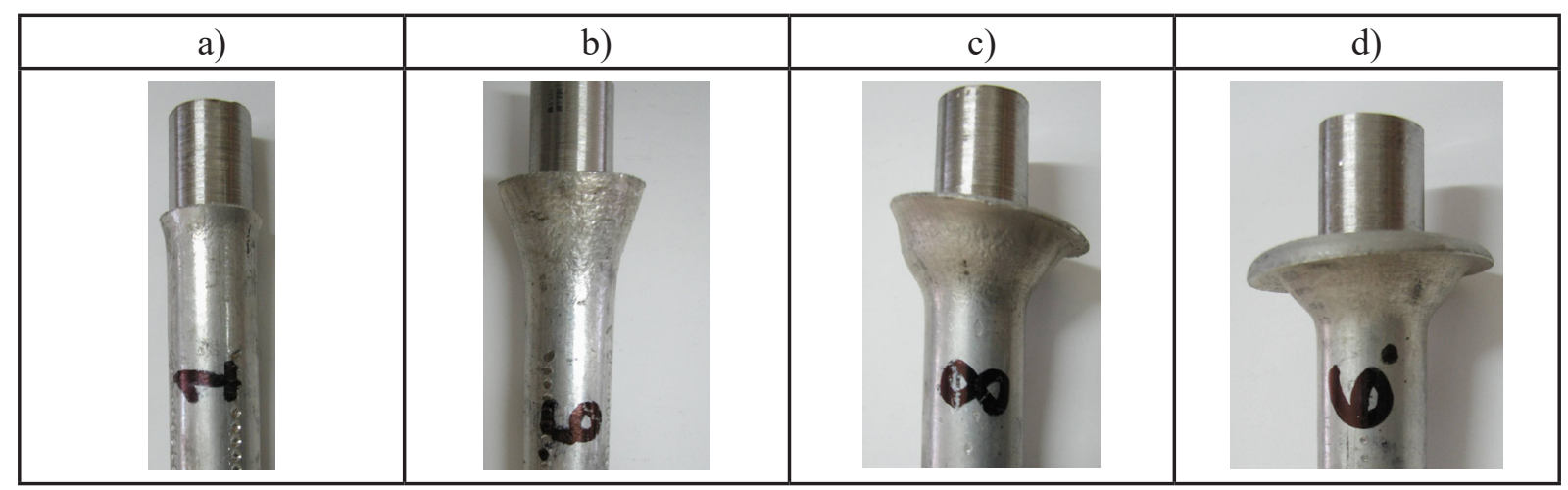

Fig. 7. Changing the geometry of the bead as a function of clamping force: $a-F t=10 \mathrm{kN}(\mathrm{tt}=7 \mathrm{~s}), \mathrm{b}-\mathrm{Ft}=$ $12.5 \mathrm{kN}(\mathrm{tt}=6.5 \mathrm{~s}), \mathrm{c}-\mathrm{Ft}=20 \mathrm{kN}(\mathrm{tt}=6.5 \mathrm{~s})$, and $\mathrm{d}-\mathrm{Ft}=30 \mathrm{kN}(\mathrm{tt}=6.5 \mathrm{~s})$.

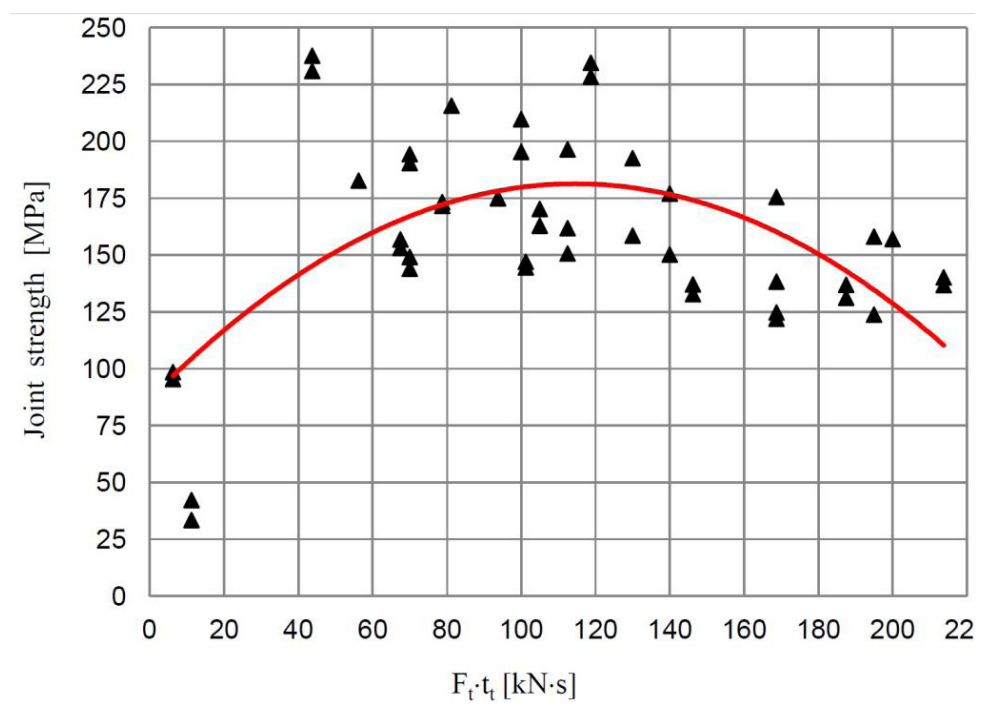

Fig. 8. Graph of tensile strength relationships of tensile joints in the product dependence Ft clamping force and friction time $t \mathrm{t}$ 
a)

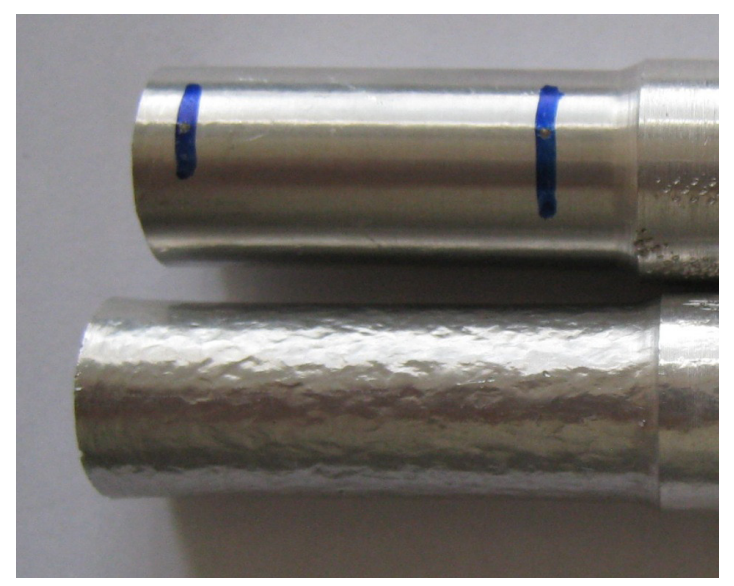

c)

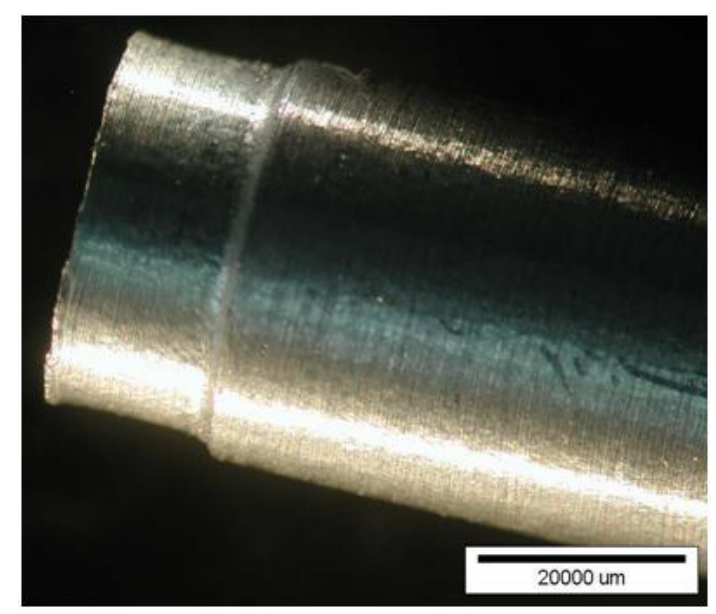

b)

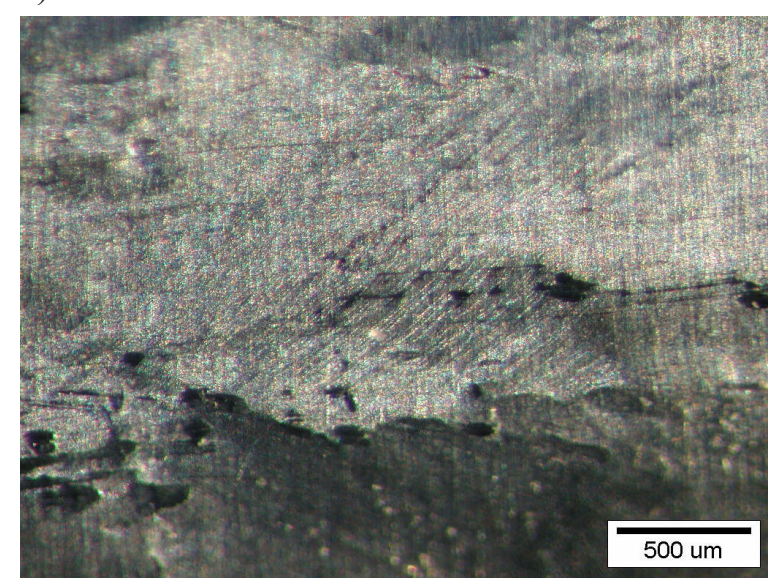

d)

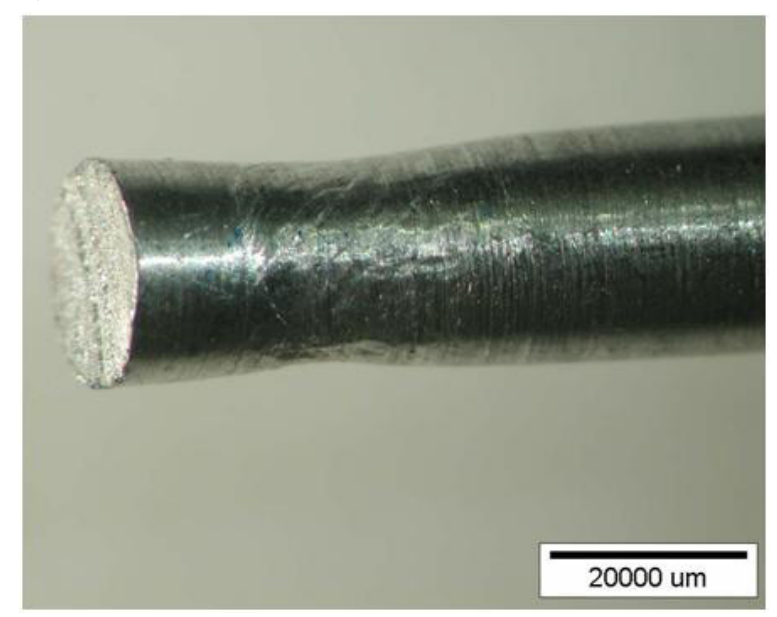

Fig. 9. Photographs illustrating the free surface of samples after testing on the testing machine: A - area of the sample before and after testing on the testing machine, $\mathrm{b}$ - faults on the side surface of the sample AlMg3 within a single grain, $\mathrm{c}$ - narrowing in the part between the terminal and the bold portion of the sample and $\mathrm{d}-$ the neck located at a considerable distance from the surface of the

become barely visible. However, compared to the relatively large scatter measurement points this observation may seem subjective, however, the welding time of $9.5 \mathrm{~s}$ leads to local "weakness" alloy AlMg3 at a distance of 5-15mm. A similar effect can be observed in the case of welding with a clamping force of $12.5 \mathrm{kN}$ of friction during the friction time $3.5 \mathrm{~s}$ and $9.5 \mathrm{~s}$. Phenomena strengthening or weakening of the local alloy AlMg3 are the result of complex interactions of thermo - mechanical. Phenomena which take place during the entire welding cycle include:

- frictional heat generation in a plane between the WHA and AlMg3,

- heat transfer from the parting line toward the WHA and AlMg3 followed by heating so that the two joined elements to a depth dependent the coefficients of thermal conductivity of WHA and AlMg3,
- reduction of the strength properties, in particular melt AlMg3, proportional to the degree of heat in the area (temperature), and also as a result of the processes taking place in the base material, such as recovery or recrystallization,

- severe plastic deformation during a step upsetting of $50 \mathrm{kN}$ force by the time $5 \mathrm{~s}$,

- possibility of recovering and / or recrystallization certain volume, depending on the density and temperature of that area.

The processes mentioned above occur in a predetermined sequence and may overlap under certain conditions at different distances from the plane of the connector, causing locally strengthening or weakening of the material which is reflected in an increase or decrease respectively, the hardness, which is directly related to the yield strength of the material. 
The aim of the hardness test carried out in parallel to the plane of the connector at a distance of $\mathrm{x}=1,2,4$ and $6 \mathrm{~mm}$ was to obtain a profile of the change in the area near the joint plane WHA - AlMg3

Comparing the graphs in the first place obtained with $22.5 \mathrm{kN}$ clamp force with the force of $12.5 \mathrm{kN}$ for readily be seen that the hardness of the course changes along the radius, for all distances $\mathrm{x}$ from the plane of the connector is flat for more strength than $12.5 \mathrm{kN}$ to $22.5 \mathrm{kN}$. This is probably due to slower and more even heating of the sample using a lower clamping force.

From the point of view of nature of the change of hardness as a function of radius $-\mathrm{r}$ distance from the plane connectors $-\mathrm{x}$ may be more complex and interesting are graphs $\mathrm{HV}=\mathrm{f}(\mathrm{r}, \mathrm{x})$ for the force $\mathrm{F}_{\mathrm{t}}=22.5 \mathrm{kN}$ for welding obtained by $0.5 \mathrm{sec}$ (Fig. 10).

a)

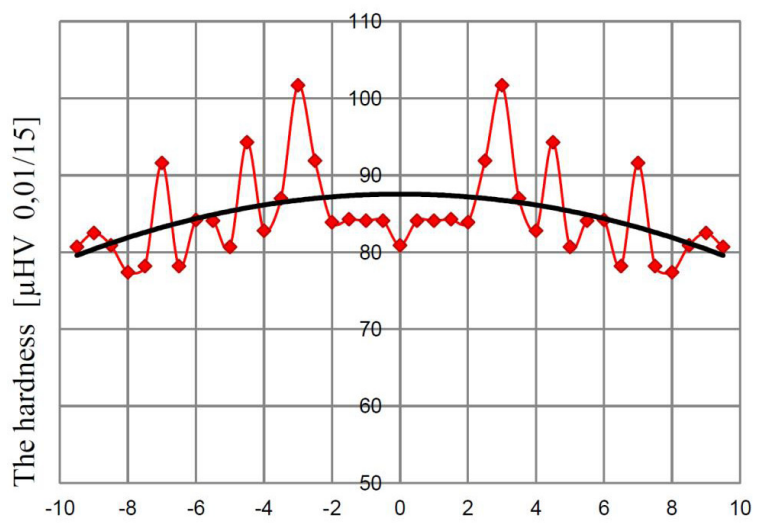

Distance from the center of the sample [mm]

c)

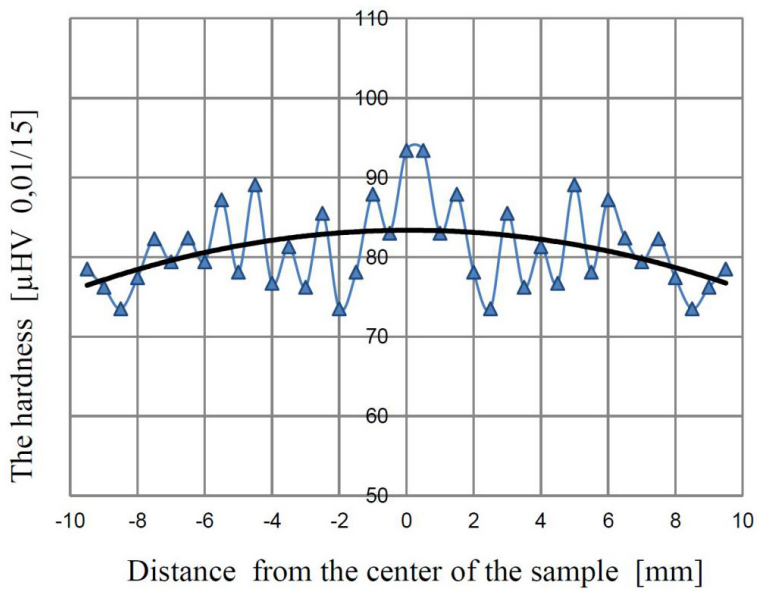

Analyzing these changes should be noted that in the case of a relatively short period of friction in the range of distances from the connector $r=$ $0.5-4 \mathrm{~mm}$ clear minimum is observed for $\mathrm{x}=1$ $\mathrm{mm}$ (Fig. 10a) and $\mathrm{x}=2 \mathrm{~mm}$ (Fig. 10b). A second minimum value of the hardness of the alloy corresponds to the "native", that is, AlMg3 melt, from which the samples for testing friction welding. It is interesting that in the case of the welding time of $0.5 \mathrm{~s}$ at a distance of $\mathrm{x}=4 \mathrm{~mm}$ is clearly visible corresponding to maximum hardness exceeding 90HV (Fig. 10c). At a distance of $x=6$ $\mathrm{mm}$ from the plane of the connector, the change of hardness as a function of radius $-r$ has a more benign course and its value fluctuates in the range of 80-90HV0, 01 It can be noted that approximately $6 \mathrm{~mm}$ from the axis is slightly lower hardness compared to the central portion and the surface of the sample.

b)

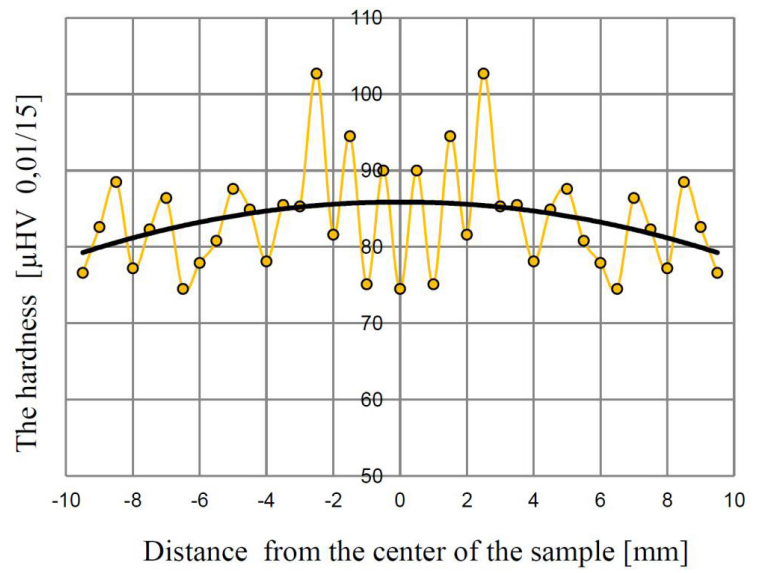

d)

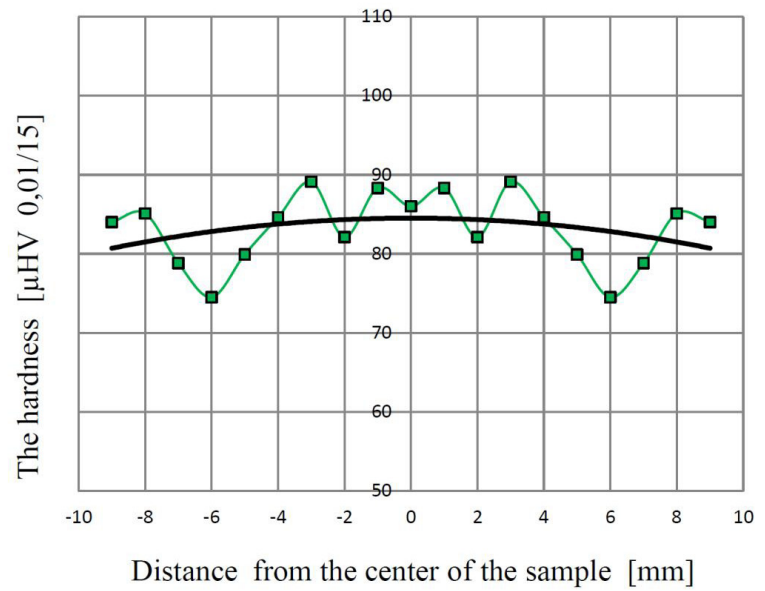

Fig. 10. Working hardness changes as a function of distance from the axis of the sample: $a-$ for $x=1 \mathrm{~mm}, \mathrm{~b}-\mathrm{x}$ $=2 \mathrm{~mm}, \mathrm{c}-\mathrm{x}=4 \mathrm{~mm}$ and $\mathrm{x}=6 \mathrm{~mm}$ for welded the sample for $0.5 \mathrm{~s}$ at a force $\mathrm{Ft}=12.5$ 
Finally, it can be concluded that in the case of welding with the force $\mathrm{F}_{\mathrm{t}}=22.5 \mathrm{kN}$ :

- friction short time $\left(\mathrm{t}_{\mathrm{t}}=0.5 \mathrm{~s}\right)$ results in a rather complex hardness distribution as a function of distance from the axis of the sample, in particular a short distance from the plane of the weld,

- complex structure hardness changes with distance from the axis of the sample revealed a local minimum of the hardness of the cylindrical sample in the axis of the joint distance from the plane $\mathrm{x}=2 \mathrm{~mm}$; this distance is above the "reversal" of extremum appears as a peak on the axis of the sample,

- prolongation of welding leads to homogenization of the hardness of both as a function of distance from the axis of the sample - and the distance $r$ from the plane of the connector $-\mathrm{x}$

Depending observed HV $=f(r, x)$ are the result of the gradual heating of the sample, which begins in the zone most distant from the axis of the sample, which is confirmed by the simulation results of the element distribution. The longer the time the friction heat is transferred into the welded components, both along the radius and the axis of the cylindrical sample. When you stop upsetting $\mathrm{AlMg} 3$ deformed by cold work in those places that were heated enough to yield stress has been exceeded. In the case of a very short time friction, eg $0.5 \mathrm{~s}$ central portion alloy $\mathrm{AlMg} 3$ (near the axis) was not heated enough, and that is probably why there was no strain hardening. This confirms that the hardness of the sample in the axis of the rod material such as that used for testing. In the case of friction welding alloy WHA$\mathrm{AlMg} 3$, as previously mentioned, the hardness as a function of distance from the axis and the plane of the sample as the connectors are much milder.

\section{CONCLUSIONS}

At the outset, we would like to note that included in the working relationship of the results are not yet completed tests designed to verify the thesis about the possibility of replacing the current method of combining bonnets ballistic aluminum alloy core WHA method of friction welding.

Consider the process of friction welding is easy to see that combining materials with different mechanical properties as the greatest effect on the item with much less resistance, in this case aluminum alloy. Figure 2 shows that a rod made of a WHA is pressed into the aluminum alloy, resulting in the shortening. Such a large reduction of the sample is not preferred. The size depends on reducing the friction welding process parameters, especially during the clamping force and friction from the time of friction. This is due to the fact that the temperature directly in the region of the join is slightly lower than the melting point of AlMg3 alloy, resulting in a significant reduction in strength properties to enable very intense plastic deformation. This temperature, in relation to the AlMg3 alloy, constituting only a small fraction of the absolute melting temperature of tungsten is sufficient for this to lead to a plastic deformation of the tungsten grains in the plane of the connector. However, the images do not illustrate this fact, it is the plastic deformation of the tungsten grains have been seen in the plane of the connection, even though the welding time does not exceed 10 seconds. The most interesting from the point of view of the performance of the connector WHA - AlMg3 are some changes in the Al.

During the friction welding the aluminum alloy is subject to a specific heat treatment - forming, by which the changes take place in it leading to changes in the microstructure, and thus the mechanical properties. Changes that can be expected are:

- possibility of a narrow diffusion zone on both sides of the plane of the connector, i.e. in the matrix aluminum and nickel-based alloy in the WHA,

- the possibility of secretion of intermetallic phases, such as phase $\beta-\mathrm{A} 18 \mathrm{Mg} 5$ or NiAl3,

- very strong plastic deformation, the effects of which can be and are probably removed by the action of heat, or recovery and recrystallization.

Without going into at this stage in the detailed analysis of the phenomena taking place during friction welding authors focused on the relationship between welding parameters and joint resistance to tearing.

With the test results presented in Table 2 were prepared according charts tensile strength (breaking strength) of the clamping force for a predetermined time $F_{t}$ friction and friction from the time $t_{t}$ a fixed value for the clamping force, which are posted on the graphs in Figure 11. In the first one (Fig. 11a) shows that for a constant clamping 
a)

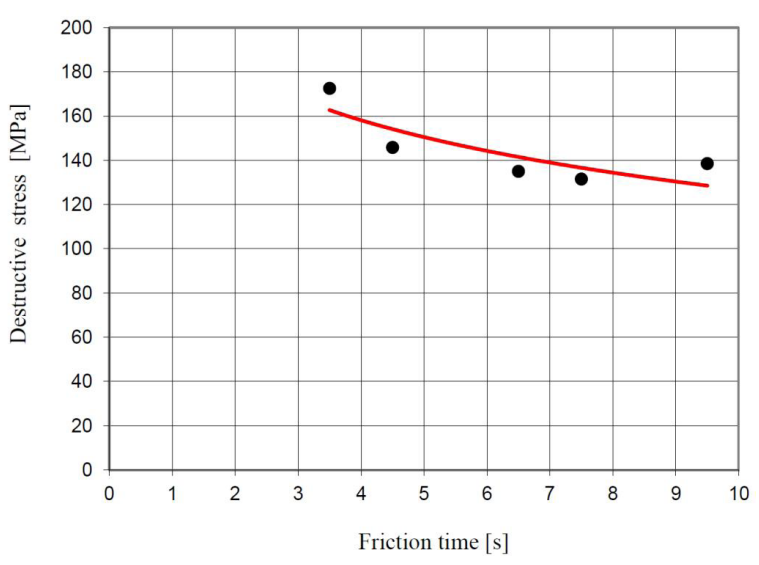

b)

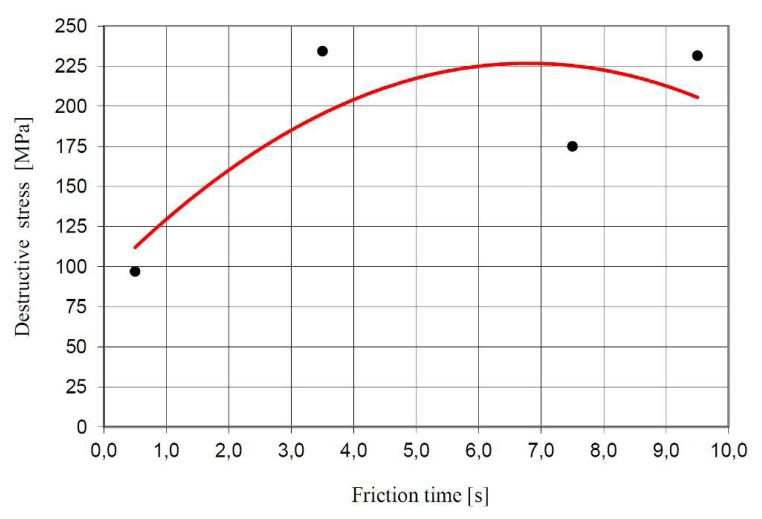

c)

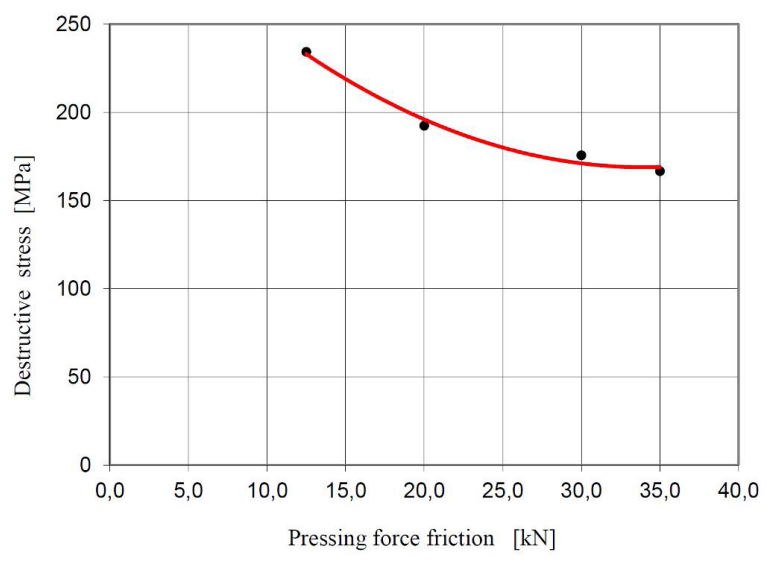

Fig. 11. The dependence of failure stress on: a - friction time at constant $\mathrm{Ft}=22.5 \mathrm{kN}$ and $\mathrm{b}-$ on friction time at constant $\mathrm{Ft}=12.5 \mathrm{kN}$ and $\mathrm{c}-$ on friction force at constant $\mathrm{tt}=3.5 \mathrm{~s}$

force $\mathrm{F}_{\mathrm{t}}=22.5 \mathrm{kN}$ increasing friction time leads to a reduction of the breaking stress. In turn, in the case of double reduce the clamping force to the value of $12.5 \mathrm{kN} \mathrm{F}_{\mathrm{t}}$ breaking stress tends to increase the strength of the joint over a range of times of friction (Fig. 11b). From the graph on Fig. $11 \mathrm{c}$ that the time constant friction amounting $t_{t}=3.5 \mathrm{~s}$, increase downforce reduces the value of breaking stress. From the above superficial considerations that joint strength WHA - AlMg3 depends both on the clamping force during the time of friction and friction. It can be assumed that the greatest strength of the joint can be obtained for downforce located in the range between $12.5 \mathrm{kN}$ and $22.5 \mathrm{kN}$ using a friction time of $3.5-5 \mathrm{sec}-$ onds. Effects on the strength of the joint depend on the complex phenomena which are a function of both time and temperature.

These processes are associated with both diffusion and its subsequent secretion process, and the reconstruction of the microstructure after strong cold-working. Excessive overheating of the material, which may be the result of a very large frictional force or pressure during a long period of friction will facilitate secretion processes of brittle intermetallic phases. Most Spin-offs are formed at the grain boundaries, and thereby weaken the joint. Very high temperature in the region of the join, not only promotes the restoration of the microstructure after cold-working and removes strengthening, deformation, but also promotes the proliferation of grains, which is not preferred.

\section{LITERATURE}

1. Alves, E. P., Neto, F. P. \& Ying An, C., 2010. Welding of AA1050 aluminum with AISI 304 stainless steel by rotary friction welding process. Journal of Aerospace Technology and Management, December, 3(2).

2. Ambroziak, A., 1998. Zgrzewanie tarciowe metali trudno topliwych w cieczy na tle innych metod spajania. Wrocław: Politechnika Wrocławska. 
3. Ambroziak, A., 2011. Zgrzewanie tarciowe materiałów o różnych właściwościach. Wrocław: Oficyna Wydawnicza Politechniki Wrocławskie.

4. Ambroziak, A., Korzeniowski, M. \& Kustroń, P., 2007. Friction welding of dissimilar metal joint with intermediate layers. Journal of Achievements in Material and Manufacturing Engineering, Tom 21.

5. Booke, G. R., 1969. Scanning Electron Microscopy. The instrument. In: Modern Diffraction and Imaging Techniques in Materials Science, eds. A. Amelinckx, R. Gevers, G. Remaut and J. Van Landuyt, North Holland Publ. Co. Amsterdam, London 1969.

6. Gregson, P. J. \& Harris, S., 2002. Friction Based Welding Technology for Aluminium. Materials
Science Forum, July, Issue 396-402, 1543-1548.

7. Kaczorowski, M., 2002. The friction welding of ductile iron (structure - properties). Acta Met. Slovaca, Tom 4, 106-111.

8. Kaczorowski, M., Ludyński, Z. \& Rafalski, M., 2006. Badania struktury kompozytów wolframowych odkształconych z dużymi prędkościami, Mat. VI Międzynarodowej Konferencji Uzbrojeniowej, Waplewo, październik 2006. s. .. Waplewo, Military University of Technology (MUT) Warsaw, 481-488.

9. Kaczorowski, M., Skoczylas, P. \& Skibicki, A., 2008. Badania wstępne możliwości zgrzewania tarciowego kompozytu wolframowego ze stalą. Rudy i metale nieżelazne, 53(7), 436-442. 